\title{
Molecular Analysis of Age and Sex-Related Gene Expression in Meniscal Tears with and without a Concomitant Anterior Cruciate Ligament Tear
}

\author{
Robert H. Brophy, MD, Muhammad Farooq Rai, PhD, Zhiqi Zhang, MD, Adelina Torgomyan, PhD, and Linda J. Sandell, PhD
} Investigation performed at the Department of Orthopaedic Surgery, Washington University School of Medicine, St. Louis, Missouri

Background: The meniscus plays critical roles in the knee, contributing to load transmission, shock absorption, and joint stability. Little is known about gene expression in meniscal tears, particularly in relation to injury pattern and patient age and sex. The purpose of this study was to test the hypothesis that gene expression in meniscal tears varies depending on patient age and sex and whether the anterior cruciate ligament $(A C L)$ is also torn.

Methods: Meniscal tissue from twenty-eight patients with an isolated meniscal tear or a meniscal tear with a concomitant ACL tear was collected at the time of clinically indicated partial meniscectomy. Messenger RNA (mRNA) expression was examined by quantitative real-time polymerase chain reaction for molecular markers of osteoarthritis including proinflammatory cytokines (interleukin [IL]-1 $\alpha$, IL-1 $\beta$, IL-6, and tumor necrosis factor-alpha [TNF $\alpha$ ]), chemokines (IL-8, CCL3, CCL3L1, CXCL1, CXCL3, CXCL6, and CCL20), aggrecanases (ADAMTS-4 [a disintegrin and metalloproteinase with thrombospondin type-4 motifs] and ADAMTS-5), matrix metalloproteinases (MMP-1, MMP-3, MMP-9, and MMP-13), transcription factors (NFKB2 [nuclear factor kappa B2], NFкBIA [NF-kappa B inhibitor alpha], and IкBA [inhibitor of kappa B alpha]), and matrix components (bone morphogenetic protein [BMP]-2, type-I collagen alpha 1 [Col1a1], Col2a1, and aggrecan).

Results: Expression of IL-1 $(p=0.02)$, ADAMTS-5 ( $p=0.001)$, MMP-1 $(p=0.007)$, MMP-9 $(p=0.002)$, MMP-13 $(p=$ $0.01)$, and NFKB2 ( $p=0.01$ ) was significantly higher in patients with a meniscal tear who were under the age of forty years than it was in those over the age of forty years. Similarly, the expression of ADAMTS-4 $(p=0.002)$, ADAMTS-5 $(p=0.02)$, MMP-1 ( $p=0.02)$, and MMP-13 ( $p=0.0002)$ was higher in patients with a meniscal tear and an ACL tear who were under the age of forty years than it was in those over forty years. In patients with a meniscal tear and an ACL tear, the expression of IL-1 $(p=0.01)$, TNF $\alpha(p=0.02)$, MMP-13 $(p=0.004)$, CCL3 $(p=0.03)$, and CCL3L1 $(p=0.03)$ was significantly higher, while that of aggrecan $(p=0.03)$ was lower, than that in patients with a meniscal tear alone. The only sex-based difference in gene expression was higher levels of CCL3L1 in female patients $(p<0.05)$ of all ages with combined injuries.

Conclusions and Clinical Relevance: These findings suggest clinically relevant differences in the response of the knee to meniscal tears on the basis of patient age and sex. Elevated expression levels of arthritis-related markers indicate an increased catabolic response in patients under forty years old. Higher expression of catabolic markers in patients with meniscal and ACL tears suggests this combined injury pattern is more likely to lead to the development of osteoarthritis. Catabolic activity in meniscal tissue may predict patients who are at risk for progression of osteoarthritis following partial meniscectomy.

Disclosure: One or more of the authors received payments or services, either directly or indirectly (i.e., via his or her institution), from a third party in support of an aspect of this work. In addition, one or more of the authors, or his or her institution, has had a financial relationship, in the thirty-six months prior to submission of this work, with an entity in the biomedical arena that could be perceived to influence or have the potential to influence what is written in this work. No author has had any other relationships, or has engaged in any other activities, that could be perceived to influence or have the potential to influence what is written in this work. The complete Disclosures of Potential Conflicts of Interest submitted by authors are always provided with the online version of the article.

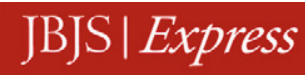

This article was chosen to appear electronically on February 22, 2012, in advance of publication in a regularly scheduled issue.

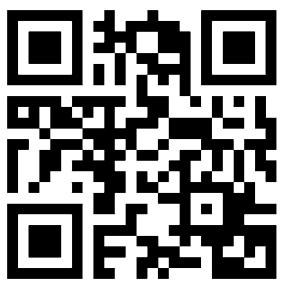

A commentary by Helen Kambic, PhD, is linked to the online version of this article at jbjs.org. 
The Journal of Bone \& Joint Surgery $\cdot$ Jbjs.org Volume 94-A · Number $5 \cdot$ March 7, 2012
Molecular Analysis of Age and Sex-Related

Gene Expression in Meniscal Tears
$\mathrm{O}$ steoarthritis of the knee is a common condition and a major cause of disability worldwide. Its complex pathogenesis remains poorly understood but appears multifactorial, with emerging evidence that osteoarthritis is not merely an articular cartilage disease, but a disease of the whole joint $^{1,2}$, involving cartilage, ${ }^{3}$ bone $e^{4}$, synovium ${ }^{5}$, and meniscus ${ }^{6,7}$. The meniscus functions as a load-bearing ${ }^{8}$ and shock-absorbing ${ }^{9}$ part of the tibiofemoral joint. Surgical procedures on the meniscus are the most commonly performed procedures in orthopaedics $^{10,11}$, and approximately $50 \%$ of people with meniscal tears have radiographic evidence of osteoarthritis ten to twenty years after injury ${ }^{12}$. In the United States alone, 690,000 partial meniscectomies and almost one million additional knee arthroscopies, most of which involve at least some debridement of the meniscus, are performed each year ${ }^{13}$. An inverse relationship has been demonstrated between the function of the knee and the amount of meniscal tissue resected ${ }^{14}$. Substantially more cartilage degeneration and osteoarthritis have been found in knees with a total meniscectomy than in those with a partial meniscectomy ${ }^{15,16}$.

We previously reported catabolic and anabolic responses to interleukin-1 (IL-1) and levels of gene expression in cartilage from patients with osteoarthritis ${ }^{17}$. Little is known about the metabolic activity of the meniscus at the time of resection and its relationship to systemic levels of markers for inflammation and for osteoarthritis. It is likely that the metabolic activity of the meniscus is affected by the same processes in the knee that affect the metabolic activity of the articular cartilage ${ }^{7}$. Furthermore, the metabolic activity of the meniscus at the time of meniscectomy may be predictive of future degenerative changes in the tibiofemoral joint. Thus, the activity of the meniscal tissue resected at the time of meniscectomy may provide important insight into the status of the overall joint health and potentially differentiate patients at risk for future progression of osteoarthritis. Gene expression in meniscal tears may depend on a number of patient-related factors, including age and sex, as well as the injury pattern. The purpose of this study was to test the hypothesis that gene expression in meniscal tears varies depending on patient age and sex and on whether the anterior cruciate ligament (ACL) is also torn.

\section{Materials and Methods}

\section{Tissue Acquisition and Processing}

All procedures were approved by the Washington University School of AMedicine human subjects institutional review board. Informed consent was obtained from all subjects. Meniscal tissue was collected at the time of clinically indicated partial meniscectomy from twenty-eight patients, including twenty with a known meniscal tear and eight with a meniscal tear and a concomitant complete ACL tear, undergoing reconstruction by one of the authors (R.H.B.) (Table I). None of the patients had advanced osteoarthritis or any additional posterior cruciate or collateral ligament injury at the time of the meniscal surgery.

The labeled specimens were transported to the laboratory from the operating room in sterile phosphate-buffered saline solution (HyClone; Thermo Fisher Scientific, Rockford, Illinois) in screw-cap containers. The tissues were weighed and washed twice with phosphate-buffered saline solution.
The tissues were put in 50-mL tubes (Falcon; BD Biosciences, San Jose, California), and $1 \mathrm{~mL}$ of TRIzol reagent (Invitrogen, Carlsbad, California) was added per 50 to $100 \mathrm{mg}$ of the tissue and kept at $-80^{\circ} \mathrm{C}$ until used for total RNA extraction.

\section{Total RNA Extraction}

Each frozen tissue specimen was thawed and homogenized directly in TRIzol reagent with use of a Polytron homogenizer (Brinkmann Instruments, Westbury, New York). Aliquots of the homogenized suspension were transferred to microfuge tubes and incubated at room temperature for five minutes to permit the complete dissociation of nucleoprotein complexes. Chloroform $(200 \mu \mathrm{L})$ was added to each microfuge tube, which was shaken for thirty seconds, incubated for two minutes at room temperature, and centrifuged at $12,000 \mathrm{~g}$ for fifteen minutes at $4^{\circ} \mathrm{C}$. The upper aqueous phase that contained RNA was moved to a clean microfuge tube, and $500 \mu \mathrm{L}$ isopropanol was added to precipitate RNA. The tubes were incubated at room temperature for ten minutes and centrifuged at 12,000 $\mathrm{g}$ for ten minutes at $4^{\circ} \mathrm{C}$. The RNA pellet was washed with $75 \%$ ethanol in water by centrifugation at $7500 \mathrm{~g}$ for five minutes at $4^{\circ} \mathrm{C}$. The pellet was dried at $37^{\circ} \mathrm{C}$, resuspended in RNase-free water (Qiagen, Valencia, California), and finally incubated at $60^{\circ} \mathrm{C}$ for ten minutes. RNA was further purified by passing through RNeasy Mini Spin Columns (Qiagen), and its yield and quality were assessed by spectrophotometry with use of a NanoDrop spectrophotometer (Thermo Fisher Scientific) and stored at $-80^{\circ} \mathrm{C}$ until reverse transcribed for complementary DNA (cDNA).

\section{Reverse Transcriptase-Polymerase Chain Reaction}

Prior to reverse transcriptase-polymerase chain reaction (RT-PCR), the isolated RNA was treated with DNase I (Invitrogen) to remove traces of contaminating DNA. In $0.2-\mathrm{mL}$ tubes, 150 to $200 \mathrm{ng}$ of total RNA, $2 \mu \mathrm{L}$ of amplification grade DNase I $(1 \mathrm{U} / \mu \mathrm{L})$, and $2 \mu \mathrm{L}$ of DNase I reaction buffer $(10 \mathrm{X})$ were added in total volume of $20 \mu \mathrm{L}$. The reaction mixture was incubated at room temperature for fifteen minutes followed by DNase I inactivation with $2 \mu \mathrm{L}$ of $25 \mathrm{mM}$ EDTA at $65^{\circ} \mathrm{C}$ for ten minutes.

The DNase-I-treated RNA was then reverse-transcribed into cDNA with use of random hexamers and the SuperScript II First-Strand Synthesis System (Invitrogen) as per the manufacturer's instructions. Briefly, $2 \mu \mathrm{L}$ of the random primer $(50 \mathrm{ng} / \mu \mathrm{L})$ and $2 \mu \mathrm{L}$ of dNTP mix $(10 \mathrm{mM})$ were added to the tube containing DNase-I-treated RNA, which was then incubated at $65^{\circ} \mathrm{C}$ for five minutes. The reaction mixture was chilled on ice, and the contents of the tubes were collected by brief centrifugation. Reverse transcription was continued after adding $14 \mu \mathrm{L}$ of master mix (0.1 M DTT [dithiothreitol], 200 units/ $\mu \mathrm{L}$ SuperScript II, and $5 \times$ first-strand buffer) and incubating at $42^{\circ} \mathrm{C}$ for fifty minutes followed by deactivation at $70^{\circ} \mathrm{C}$ for fifteen minutes.

\section{Quantitative Real-Time PCR}

Transcript sequences for the housekeeping and target genes were obtained from the National Center for Biotechnology Information (NCBI; www. ncbi.nlm.nih.gov/). Primer sequences were designed by Primer Express 3 (Applied Biosystems, Foster City, California), and NCBI BLAST (Basic Local Alignment Search Tool) searches were performed for all primer sequences to confirm gene specificity. Custom-designed primers (see Appendix) were obtained from Invitrogen. Gene expression analysis was performed on a 7500 Fast Real-Time PCR System (Applied Biosystems). The housekeeping gene glyceraldehyde 3-phosphate dehydrogenase (GAPDH) acted as an endogenous reference gene for normalization of fluorescence threshold $\left(C_{t}\right)$ values of target genes. In a $20-\mu \mathrm{L}$ reaction volume, $10 \mu \mathrm{L}$ of SYBR Green PCR Master Mix (Applied Biosystems), $1.5 \mu \mathrm{L}$ of cDNA, and $200 \mathrm{nM}$ of primers were added. Samples were amplified with an initial activation step at $95^{\circ} \mathrm{C}$ for ten minutes, followed by forty cycles of denaturation at $95^{\circ} \mathrm{C}$ for fifteen seconds and annealing at $60^{\circ} \mathrm{C}$ for one minute. The $\mathrm{C}_{t}$ (fluorescence threshold) values for GAPDH and the genes of interest were measured and normalized to GAPDH for each sample $\left(\Delta \mathrm{C}_{t}\right)$. The comparative gene 
A

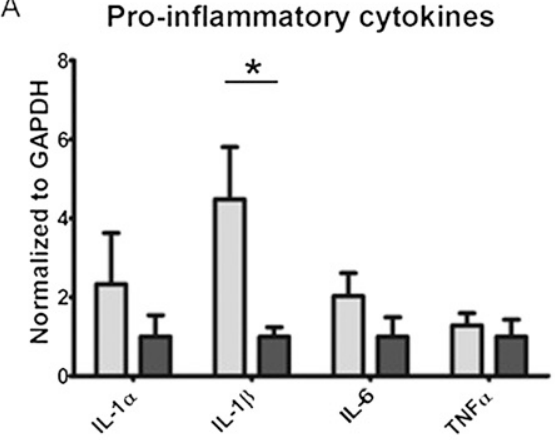

D

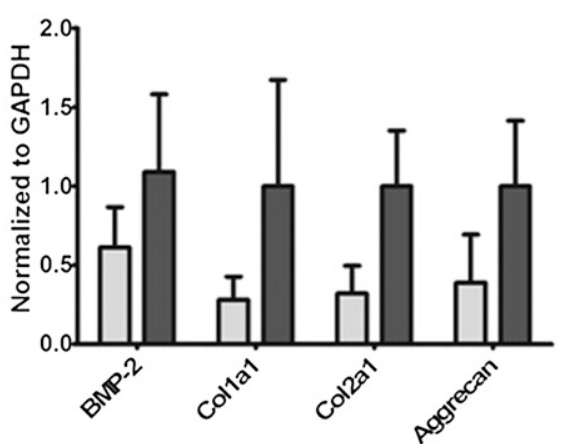

B

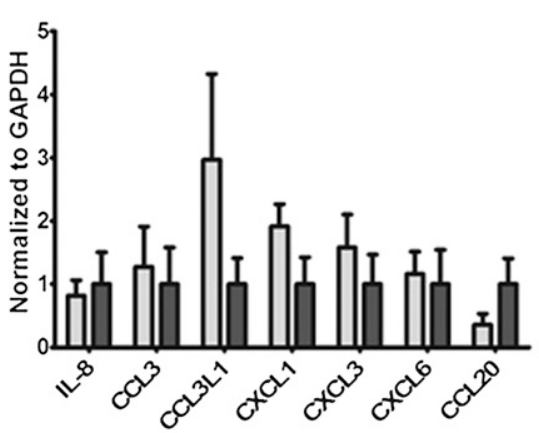

E

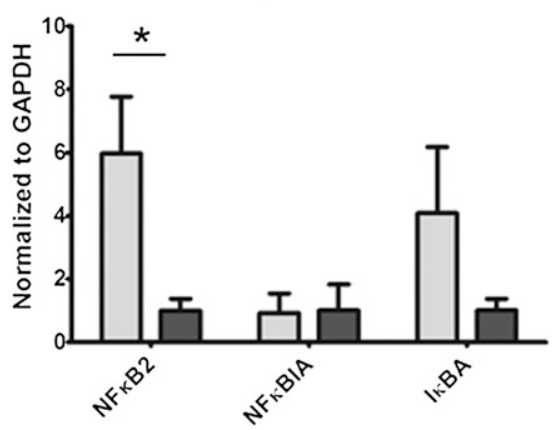

C Matrix degrading enzymes

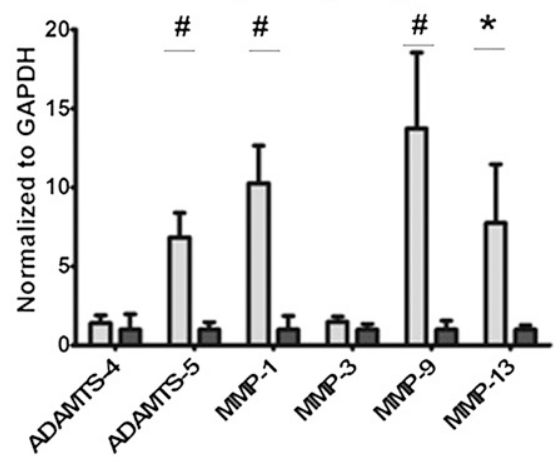

Fig. 1

Messenger RNA gene expression of cytokines (IL-1 $\alpha$, IL-1 $\beta$, IL-6, and TNF $\alpha$ ), chemokines (IL-8, CCL3, CCL3L1, CXCL1, CXCL-6, and CCL20), matrix-

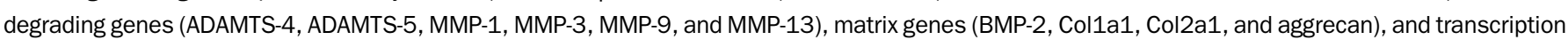

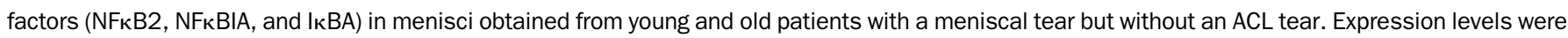

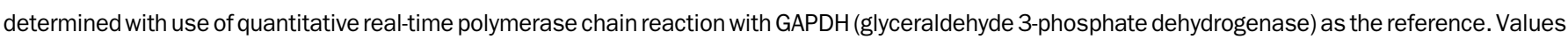
are given as the mean and the standard error of the mean. ${ }^{*} p<0.05$. $\# p<0.01$.

expression was calculated by $\mathrm{X}=2^{-\Delta \Delta \mathrm{Ct}}$, where $\Delta \Delta \mathrm{C}_{\mathrm{t}}$ represents $\Delta \mathrm{C}_{\mathrm{t}}$ (target) $\Delta \mathrm{C}_{\mathrm{t}}$ (reference).

\section{Statistical Analysis}

Gene expression was compared by patient age and sex and by injury pattern (meniscal tear compared with combined meniscal and ACL tears). Patients under forty years old are more likely to sustain traumatic meniscal tears, while the prevalence of degenerative tears increases with patient age ${ }^{7}$. Since torn menisci in patients over forty years of age have been shown to have lower cellularity compared with torn menisci in patients under forty years of age ${ }^{18}$, we compared gene expression in patients under forty years (young) with gene expression in patients forty years and older (mature). Significance between the groups was determined with use of a two-tailed unpaired $t$ test with unequal variance, and significance levels were calculated with the Mann-Whitney U test. Significance based on sex was determined by analysis of variance followed by Bonferroni post hoc analyses. All statistics were performed with use of GraphPad (GraphPad Software, San Diego, California). A $\mathrm{p}$ value of $<0.05$ was considered significant. Values presented in the text, figures, and tables are given as the mean and the standard error of the mean.

\section{Source of Funding}

Funding for this study was provided by a grant from the Orthopaedic Research and Education Foundation (R.H.B.), National Institute of Arthritis and Musculoskeletal and Skin Diseases grant RO1-AR036994 (L.J.S.), and National Institutes of Health (NIH) Grand Opportunity Grant RC2-
AR058978 (L.J.S.). The NIH also provided salary support (T32-AR060719) for M.F.R.

\section{Results}

Age-Related Gene Expression from Meniscal Tear Specimens Datients with a meniscal tear who were under forty years old and those who were forty years or older were compared with respect to the expression of messenger RNA (mRNA) for proinflammatory cytokines involved in osteoarthritis. The only significant difference was higher levels of IL- $1 \beta$ in the young patients compared with that in the mature patients $(\mathrm{p}=0.02)$ (Fig. 1-A). There were no significant differences in the expression of chemokines between these two groups (Fig. 1-B). Gene expression of matrix-degrading enzymes, such as aggrecanases and metalloproteinases, demonstrated significantly higher levels of ADAMTS-5 (a disintegrin and metalloproteinase with thrombospondin type- 5 motifs $)(p=0.001)$ as well as matrix metalloproteinase (MMP)$1(\mathrm{p}=0.007)$, MMP-9 $(\mathrm{p}=0.002)$, and MMP-13 $(\mathrm{p}=0.01)$ in patients under forty years of age (Fig. 1-C). There were no significant differences in the expression of mRNA for matrix molecules that constitute menisci (Fig. 1-D). The expression of transcription factors involved in the osteoarthritis pathway 
The Journal of Bone \& Joint Surgery Jbjs. org Volume 94-A - Number $5 \cdot$ March 7, 2012
Molecular Analysis of Age and Sex-Related

Gene Expression in Meniscal Tears

\begin{tabular}{|lcc|}
\hline TABLE I Demographic Data & & \\
\hline & $\begin{array}{c}\text { Meniscal } \\
\text { Tear }\end{array}$ & $\begin{array}{c}\text { Meniscal Tear } \\
\text { and ACL Tear* }\end{array}$ \\
\hline All patients & & \\
Male & 11 & 5 \\
Female & 9 & 3 \\
Total & 20 & 8 \\
Mean age (range) (yr) & $41.5(14-60)$ & $26.8(16-59)$ \\
Patients $<40$ yr old & & 4 \\
Male & 3 & 2 \\
Female & 5 & 6 \\
Total & 8 & $19(16-27)$ \\
Mean age (range) (yr) & $25.5(14-36)$ & 1 \\
Patients $\geq 40$ yr old & & 1 \\
Male & 8 & 2 \\
Female & 4 & $50.5(42-59)$ \\
Total & 12 & \\
Mean age (range) (yr) & $52.2(41-60)$ & \\
\hline *ACL = anterior cruciate ligament. & & \\
\hline
\end{tabular}

demonstrated significantly higher levels of NFкB2 (nuclear factor kappa B2) $(\mathrm{p}=0.01)$ in patients under forty years (Fig. $1-\mathrm{E})$.

\section{Age-Related Gene Expression from Meniscal Tear and ACL Tear Specimens}

There was no significant age-related difference in the expression of proinflammatory cytokines (Fig. 2-A) or chemokines (Fig. 2-B) between young and mature patients with a combined injury pattern (a meniscal tear and an ACL tear). However, the expression of both ADAMTS- $4(\mathrm{p}=0.002)$ and ADAMTS-5 $(\mathrm{p}=0.02)$ was significantly higher in patients with a combined injury pattern who were under forty years old than it was in those over forty years old. The expression levels of MMP-1 ( $p=0.02)$ and MMP- $13(\mathrm{p}=0.0002)$ were higher in patients with a combined injury pattern who were under forty years old than in those who were over forty (Fig. $2-\mathrm{C})$. There was a higher expression of matrix genes in the patients over forty years old. Although all of the genes for matrix components were expressed at lower levels in the patients under forty years old, the age-related difference was not significant for these genes (Fig. 2-D). For the transcription
A

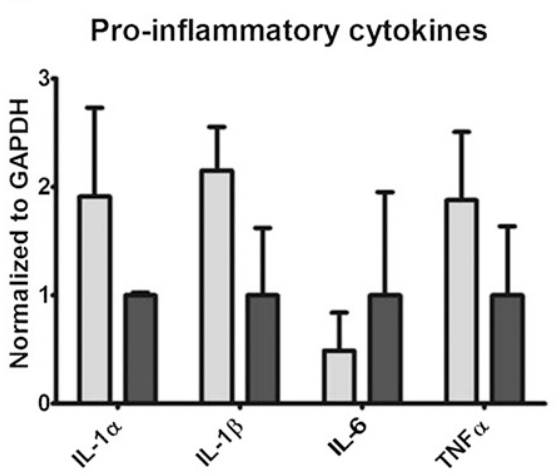

D

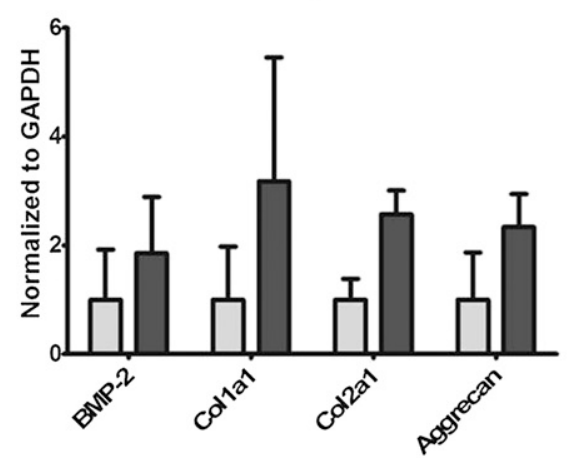

B

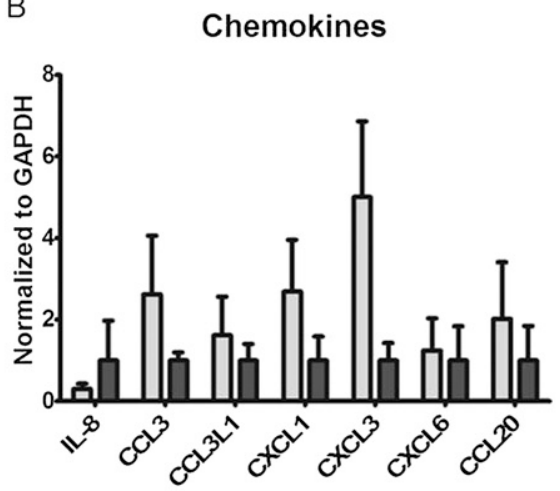

E

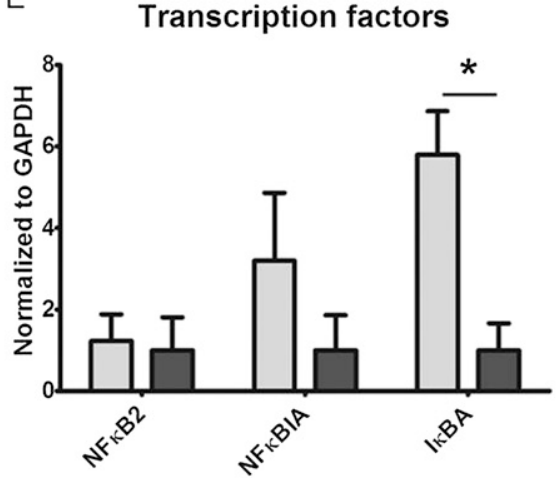

C Matrix degrading enzymes

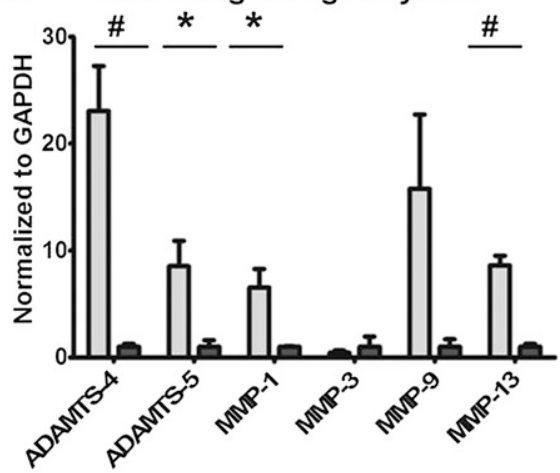

- Under 40

Over 40

Fig. 2

Messenger RNA gene expression of cytokines (IL-1 $\alpha$, IL-1 $\beta$, IL-6, and TNF $\alpha$ ), chemokines (IL-8, CCL3, CCL3L1, CXCL1, CXCL-6, and CCL20), matrix-

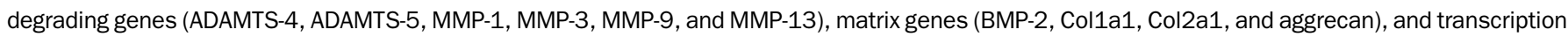

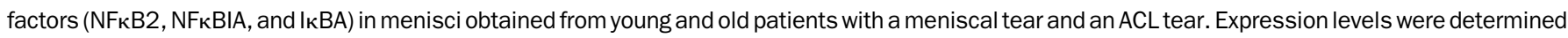

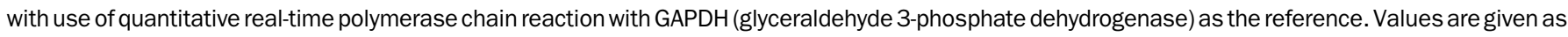
the mean and the standard error of the mean. $* \mathrm{p}<0.05 . \# p<0.01$. 

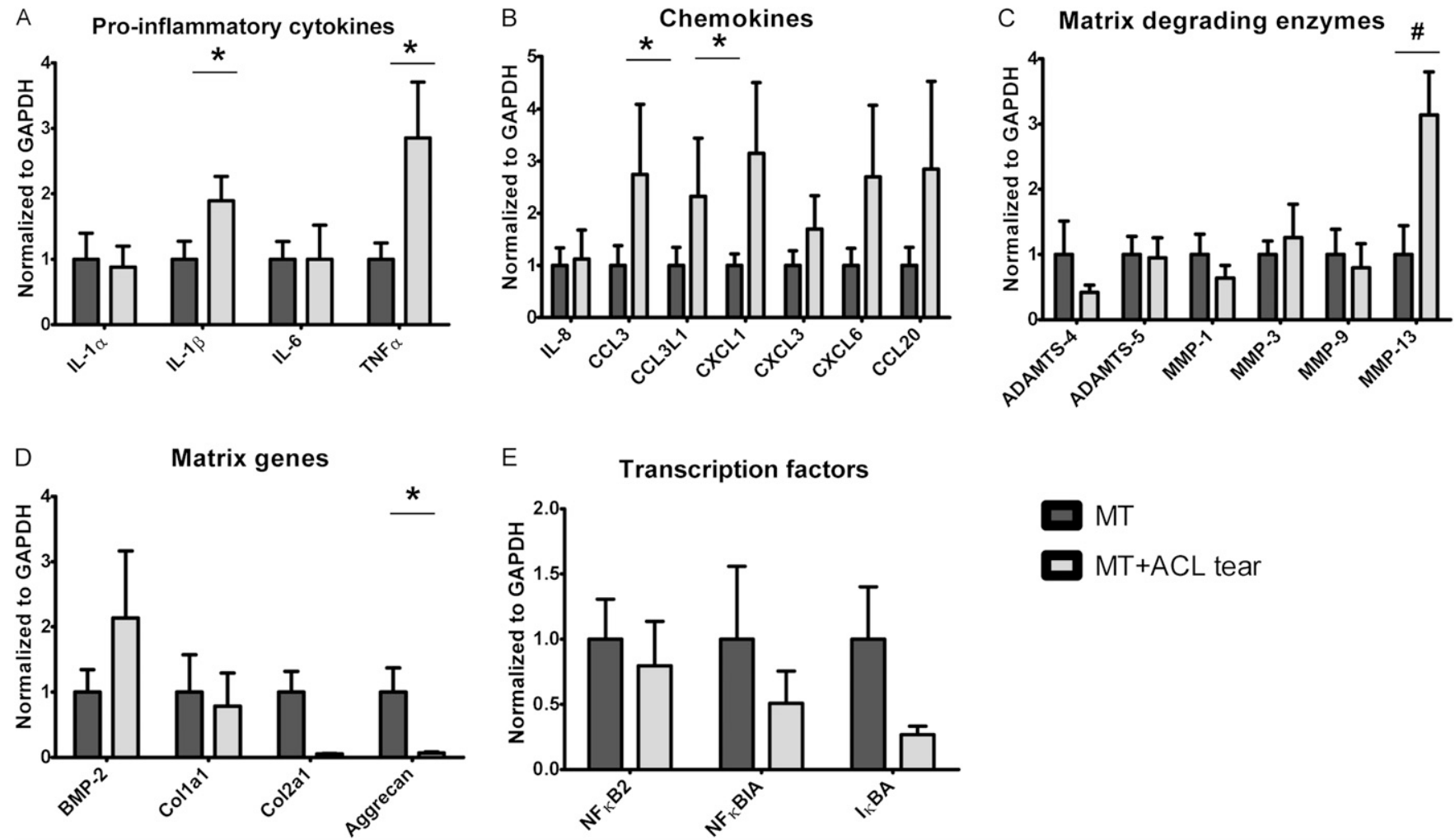

E
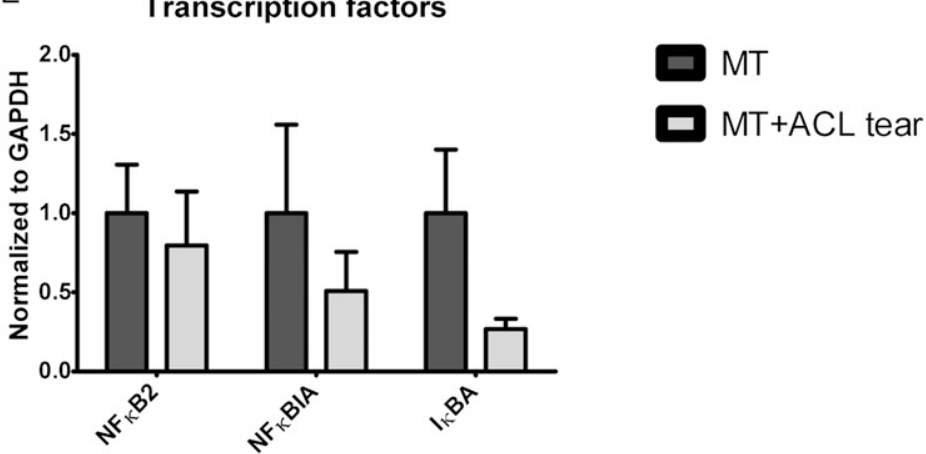

Messenger RNA gene expression of cytokines (IL-1 $\alpha$, IL-1 $\beta$, IL-6, and TNF $\alpha$ ), chemokines (IL-8, CCL3, CCL3L1, CXCL1, CXCL-6, and CCL20), matrixdegrading genes (ADAMTS-4, ADAMTS-5, MMP-1, MMP-3, MMP-9, and MMP-13), matrix genes (BMP-2, Col1a1, Col2a1, and aggrecan), and transcription factors (NFKB2, NFKBIA, and I $\mathrm{kBA}$ ) in menisci obtained from patients with combined meniscal and ACL tears (MT + ACL) and those without an ACL tear (MT). Expression levels were determined with use of quantitative real-time polymerase chain reaction with GAPDH (glyceraldehyde 3-phosphate dehydrogenase) as the reference. Values are given as the mean and the standard error of the mean. ${ }^{*} p<0.05 . \# p<0.01$.

factors, the gene expression was significantly higher for ІкBA (inhibitor of kappa B alpha) $(\mathrm{p}=0.01)$ in patients under forty years old, although NFkBIA (NF-kappa B inhibitor alpha) and NFкB2 were increased in these patients by 3.2-fold and 1.2-fold (Fig. 2-E).

\section{Comparison of Gene Expression Between the Group with a Meniscal Tear and the Group with a Meniscal Tear and an ACL Tear}

When we compared the tissues from patients with a meniscal tear and the tissues from patients with a meniscal tear and an ACL tear with respect to gene expression of proinflammatory cytokines, the expression levels of IL- $1 \alpha$ and IL- 6 were equal in both groups. There was a significant increase in the expression of IL-1 $\beta(\mathrm{p}=0.01)$ and tumor necrosis factor alpha $(\mathrm{TNF} \alpha)(\mathrm{p}=0.02)$ in the tissue from the patients with a meniscal tear and an ACL tear compared with that from patients with a meniscal tear alone (Fig. 3-A). For the chemokines, there was a significantly higher expression of CCL3 ( $\mathrm{p}=$ $0.03)$ and CCL3L1 $(\mathrm{p}=0.03)$ in the tissue from patients with a combined meniscal and ACL tear. The expression of IL-8 was equal in both groups (Fig. 3-B). The expression of MMP-13 $(\mathrm{p}=0.004)$ was higher in the meniscal and ACL tear group, but none of the other genes for matrix-degrading enzymes were significantly different between the two groups. Also, the expression of MMP-3 was slightly higher (1.3-fold) in the meniscal and ACL tear group. In contrast, the expression was less, although it was not significantly different, for ADAMTS-4 (2.4-fold), MMP-1 (1.6-fold), and MMP-9 (1.3-fold) in this group. ADAMTS-5 was equally expressed in both groups (Fig. 3-C). From the genes for matrix components (Fig. 3-D) as well as transcription factors (Fig. 3-E), only aggrecan was significantly $(\mathrm{p}=0.03)$ lower in patients with a combined meniscal and ACL tear. Except for the bone morphogenetic protein (BMP)-2, the expression of all other matrix genes and transcription factors was less in the combined meniscal and ACL tear group. However, these differences in gene expression were not significant.

\section{Sex-Based Differences in Gene Expression}

The analysis of variance results showed that expression of CCL3L1 was significantly greater in female patients with combined meniscal and ACL tears than in male patients with combined meniscal and ACL tears $(\mathrm{p}<0.05)$ as well as in male $(\mathrm{p}<0.01)$ and female patients $(\mathrm{p}<0.001)$ from the isolated meniscal tear group. There was no significant difference among 


\section{TABLE II Normalized Expression Levels in Menisci Obtained at the Time of Clinically Indicated Partial Meniscectomy in Patients with} and without a Concomitant ACL Tear

\begin{tabular}{|c|c|c|c|c|}
\hline Genes & \multicolumn{2}{|c|}{ Meniscal Tear* } & \multicolumn{2}{|c|}{ Meniscal Tear and ACL Tear* } \\
\hline \multicolumn{5}{|c|}{ Proinflammatory cytokines } \\
\hline $\mathrm{IL}-1 \alpha$ & $0.89 \pm 0.61$ & $1.00 \pm 0.41$ & $0.67 \pm 0.17$ & $1.09 \pm 0.33$ \\
\hline IL-1 $\beta$ & $0.56 \pm 0.23$ & $1.00 \pm 0.37$ & $1.01 \pm 0.21$ & $2.14 \pm 0.18$ \\
\hline IL-6 & $0.72 \pm 0.31$ & $1.00 \pm 0.36$ & $0.72 \pm 0.50$ & $1.05 \pm 0.39$ \\
\hline \multicolumn{5}{|l|}{ Chemokines } \\
\hline $\mathrm{IL}-8$ & $2.38 \pm 1.00$ & $1.00 \pm 0.45$ & $2.83 \pm 1.46$ & $0.54 \pm 0.15$ \\
\hline CCL3 & $0.22 \pm 0.06$ & $1.00 \pm 0.45$ & $1.53 \pm 1.15$ & $1.64 \pm 0.42$ \\
\hline CCL3L1 & $1.66 \pm 0.80 \dagger$ & $1.00 \pm 0.39 \neq$ & $1.38 \pm 0.42 \S$ & $6.14 \pm 1.49 \dagger \neq \S$ \\
\hline CXCL1 & $1.05 \pm 0.37$ & $1.00 \pm 0.26$ & $3.18 \pm 1.66$ & $3.31 \pm 1.19$ \\
\hline CXCL3 & $0.32 \pm 0.06$ & $1.00 \pm 0.35$ & $0.85 \pm 0.39$ & $1.40 \pm 0.37$ \\
\hline ADAMTS-4 & $0.14 \pm 0.09$ & $1.00 \pm 0.56$ & $0.22 \pm 0.07$ & $0.22 \pm 0.05$ \\
\hline ADAMTS-5 & $0.38 \pm 0.21$ & $1.00 \pm 0.29$ & $0.71 \pm 0.30$ & $0.47 \pm 0.09$ \\
\hline MMP-1 & $0.46 \pm 0.23$ & $1.00 \pm 0.40$ & $0.48 \pm 0.19$ & $0.39 \pm 0.09$ \\
\hline MMP-3 & $0.96 \pm 0.29$ & $1.00 \pm 0.29$ & $0.42 \pm 0.11$ & $2.59 \pm 0.36$ \\
\hline MMP-9 & $0.58 \pm 0.35$ & $1.00 \pm 0.52$ & $0.39 \pm 0.20$ & $0.99 \pm 0.29$ \\
\hline MMP-13 & $1.24 \pm 0.89$ & $1.00 \pm 0.30$ & $4.02 \pm 1.05$ & $2.79 \pm 0.42$ \\
\hline \multicolumn{5}{|l|}{ Matrix genes } \\
\hline BMP-2 & $0.59 \pm 0.39$ & $1.00 \pm 0.36$ & $1.14 \pm 0.92$ & $2.53 \pm 0.63$ \\
\hline Col1a1 & $0.94 \pm 0.90$ & $1.00 \pm 0.63$ & $0.37 \pm 0.21$ & $1.41 \pm 0.53$ \\
\hline Col2a1 & $1.25 \pm 0.57$ & $1.00 \pm 0.44$ & $0.06 \pm 0.02$ & $0.05 \pm 0.003$ \\
\hline Aggrecan & $0.51 \pm 0.22$ & $1.00 \pm 0.55$ & $0.05 \pm 0.01$ & $0.05 \pm 0.01$ \\
\hline
\end{tabular}

*Data expressed as the mean and the standard error of mean. $A C L=$ anterior cruciate ligament. $†$ The difference was significant $(p<0.01)$. $\neq$ The difference was significant $(p<0.001)$. §The difference was significant $(p<0.05)$.

the expression of other genes based on sex and pattern of injury (Table II).

\section{Discussion}

ene expression in meniscal tears varies by patient age, sex, $\mathbf{J}$ and injury pattern. Younger patients (those under forty years of age) have greater expression of degradative enzymes and NFkB2, a transcription factor involved in the inflammatory and catabolic events in osteoarthritis. The presence of an associated ACL tear increases the expression of the proinflammatory cytokines IL- $1 \beta$ and TNF $\alpha$, chemokines CCL3 and CCL3L1, and the matrix-degrading enzyme MMP-13. Combined meniscal and ACL injury also results in less expression for the matrix component aggrecan in meniscal tissue compared with an isolated meniscal tear. Thus, the meniscus ap- pears to undergo more substantial changes in gene expression as a result of combined injury.

There is a significant effect of patient age and sex, as well as injury pattern, on the expression of osteoarthritis-related genes in the human meniscus. The expression pattern of multiple proinflammatory cytokines, chemokines, matrix-degrading enzymes, matrix genes, and transcription factors is an important consideration in the molecular characterization of osteoarthritis ${ }^{2}$. Among patients with an isolated meniscal tear, those younger than forty years had elevated levels of several of the osteoarthritis-related genes compared with patients older than forty years. For example, IL-1 $\beta$, ADAMTS-5, MMP-1, MMP-9, MMP-13, and NFкB2 were expressed significantly higher in meniscal tears from patients under forty years. In parallel, although not significant, the expression of matrix genes BMP-2, 
The Journal of Bone \& Joint Surgery $\cdot$ Jbjs.org Volume 94-A · Number $5 \cdot$ March 7, 2012
Molecular Analysis of Age and Sex-Related

Gene Expression in Meniscal Tears
type-I collagen alpha 1 (Col1a1), Col2a1, and aggrecan was lower in patients under forty years than those over forty. Interestingly, none of the arthritis-related genes was upregulated in patients over forty except for IL-8 and CCL20, although their expression was also not significant. These findings indicate that the meniscus in young individuals has more intrinsic response and is more prone to inflammatory changes after an isolated meniscal tear. This observation is consistent with the greater prevalence of traumatic tears in younger patients ${ }^{7}$ that are associated with an increased risk of osteoarthritis development ${ }^{19}$, and it provides a molecular rationale for the increased risk of osteoarthritis.

The age-related gene expression pattern of meniscal tears associated with ACL rupture revealed that the elevated expression of genes in patients under forty years of age was limited to ADAMTS-4, ADAMTS-5, MMP-1, MMP-13, and ІкBA. With the exception of ADAMTS-4 and IкBA, all other genes were also significantly upregulated in patients under forty years old with an isolated meniscal tear. Thus, it appears that aggrecanases and matrix metalloproteinases are consistently expressed at higher levels in patients under forty years old with meniscal tears, with or without a concomitant ACL tear.

Articular cartilage degeneration in osteoarthritis is thought to result from a metabolic imbalance in the joint characterized by the upregulation of aggrecanases (especially ADAMTS-4 and ADAMTS-5), resulting in the degradation of aggrecan ${ }^{20}$. Similarly, the excessive cleavage of type-II collagen in osteoarthritis is also assumed to be caused by the upregulation of the synthesis and activities of collagenases ${ }^{21}$, in particular MMP- $13^{22}$. Both ADAMTS-4 and ADAMTS-5 are major aggrecan-degrading enzymes and have been previously implicated in the degradation of articular cartilage $e^{23,24}$. The elevated expression of these genes in meniscal tissues suggests that they may play a pivotal role in subsequent joint degeneration.

Our results suggest that early changes in the joint following a meniscal tear include increased expression of matrix-degrading genes. This overexpression likely results in the degradation of both aggrecan and collagen. There is also a decreased expression of matrix genes in menisci with isolated tears. However, as mentioned previously, not many proinflammatory genes differed between young and mature patients with combined meniscal and ACL injury. Only MMP-13 was expressed at significantly higher levels in patients with a combined meniscal and ACL tear compared with those with an isolated meniscal tear. Conversely, the expression of aggrecan and Col2al was lower in the combined meniscal and ACL tear group, which could explain increased degradation of extracellular matrix following ACL rupture with less potential for repair. Furthermore, the expression of IL-1 $\beta$ and TNF $\alpha$ was also significantly higher in patients with a meniscal and ACL tear. These master proinflammatory cytokines play key roles in the initiation and progression of the osteoarthritis disease process $^{25-27}$. Their increased expression signifies the severity of inflammation associated with a combined ACL and meniscal injury and likely explains elevated degradation of extracellular matrix.
Only two chemokines, CCL3 and CCL3L1, were significantly upregulated in patients with meniscal and ACL tears. Both of these chemokines are proinflammatory in nature and are known to enhance the inflammatory responses ${ }^{28,29}$, and they may be involved in articular cartilage destruction. This also indicates that a combined meniscal and ACL tear has a greater acute inflammatory response compared with an isolated meniscal tear.

Further information can be derived through the expression pattern of transcription factors involved in the inflammatory cascade of arthritis. Significantly higher levels of $\mathrm{NF \kappa B} 2$ in patients with a meniscal tear who were under forty years of age correlated well with the higher expression of downstream inflammatory genes in these patients. However, substantially higher expression of IкBA in patients with a meniscal and ACL tear who were under forty years might indicate an early NFкB-dependent upregulation of ІкBA. This overexpression of IкBA further explains the lower levels of $\mathrm{NF \kappa B} 2$ in these patients through a negative feedback loop mechanism.

The findings from the present study are clinically relevant in several ways. First, these differences in gene expression may relate to the worse long-term clinical outcomes after meniscal repair seen in older patients ${ }^{30}$. Although short-term clinical success rates are good in patients older than forty years ${ }^{31}$, these patients have reportedly lower rates of meniscal healing and higher long-term failure rates after repair. As a lack of viable cells in the meniscus is associated with degeneration and repeat tearing, one possible physiologic reason for higher late failure rates in older patients may be the decreased intrinsic and perimeniscal cellularity found in the torn menisci of this patient group ${ }^{18}$. Differences in gene expression and intrinsic inflammation may contribute to this difference in healing potential as well. The relationship between a catabolic response of the meniscus at the time of meniscal resection and patient age could be used in the future to help guide the clinical decision of whether to repair or resect the torn meniscus.

Perhaps more importantly, the level of catabolic activity may allow for the classification of patients who in the future could be predicted to develop progression of osteoarthritis following partial meniscectomy. This identification of patients at risk for progression of osteoarthritis following partial meniscectomy could facilitate studies of possible interventions such as activity modification, weight loss, pharmaceuticals, injections, or meniscal replacement or transplantation to slow or arrest this progression to osteoarthritis.

It has been widely reported that osteoarthritis is more common in women than in $\operatorname{men}^{32,33}$. It has been reported that meniscal tears, diagnosed by magnetic resonance imaging, are very common in older women with knee osteoarthritis, particularly in the medial compartment of the knee. However, the reasons for this association have been unclear $^{34}$. On the basis of our findings, a reasonable expectation would have been higher expression of osteoarthritis-related genes after meniscal tears in female patients. However, surprisingly, there was no strong evidence to support this hypothesis. The only osteoarthritis- 
The Journal of Bone \& Joint Surgery - Jbjs.org Volume 94-A · Number $5 \cdot$ March 7, 2012
Molecular Analysis of Age and Sex-Related

Gene Expression in Meniscal Tears related gene that was significantly greater in females was CCL3L1. The clinical implications of this finding are not clear at this time and warrant further investigation.

This study has a number of limitations. First, all of these values are from injured menisci. There are no data on values in healthy, uninjured menisci for comparison. Second, a variety of other factors such as general health conditions, body mass index, smoking status, joint health, and patient variance could influence gene expression in meniscal tissue. The relationship of meniscal gene expression to articular cartilage degeneration in the joint and potential progression of cartilage degeneration is unknown. Finally, we did not account for the compartment of the torn meniscus (medial vs. lateral), the location of the tear within the meniscus, or the synovial fluid, all of which could potentially relate to gene expression.

In summary, gene expression in meniscal tears varies by patient age, sex, and injury pattern. Our findings suggest that elevated expression levels of osteoarthritis-specific markers indicate an increased catabolic (inflammatory) response in patients under forty years of age with meniscal tears. Furthermore, higher expression of inflammatory markers in patients with a combined meniscal and ACL injury suggests the combined injury pattern is more likely to lead to the development of osteoarthritis. Catabolic activity may be predictive of patients at risk for progression of osteoarthritis following partial meniscectomy and ACL reconstruction. Further investigation of gene expression in torn menisci from these patients may reveal novel disease markers for early osteoarthritis and potentially identify new therapeutic targets for therapy to delay or prevent osteoarthritis after meniscal injury.

\section{Appendix}

eA A table showing the primers for quantitative real-time version of this article as a data supplement at jbjs.org.

Robert H. Brophy, MD

Muhammad Farooq Rai, PhD

Zhiqi Zhang, MD

Adelina Torgomyan, $\mathrm{PhD}$

Linda J. Sandell, PhD

Departments of Orthopaedic Surgery

(R.H.B., M.F.R., Z.Z., A.T., and L.J.S.)

and Cell Biology and Physiology (L.J.S.),

Washington University School of Medicine,

14532 South Outer Forty Drive,

Chesterfield, MO 63017

\section{References}

1. Samuels J, Krasnokutsky S, Abramson SB. Osteoarthritis: a tale of three tissues. Bull NYU Hosp Jt Dis. 2008;66:244-50.

2. Sun Y, Mauerhan DR, Honeycutt PR, Kneisl JS, Norton JH, Hanley EN Jr, Gruber $\mathrm{HE}$. Analysis of meniscal degeneration and meniscal gene expression. BMC Musculoskelet Disord. 2010;11:19.

3. Buckwalter JA, Mankin $\mathrm{HJ}$. Articular cartilage: degeneration and osteoarthritis, repair, regeneration, and transplantation. Instr Course Lect. 1998;47:487-504.

4. Rogers J, Shepstone L, Dieppe P. Is osteoarthritis a systemic disorder of bone? Arthritis Rheum. 2004;50:452-7.

5. Kato $\mathrm{H}$, Matsumine A, Wakabayashi $\mathrm{T}$, Hasegawa M, Sudo A, Shintani K, Fukuda A, Kato K, Ide N, Orita S, Hasegawa T, Matsumura C, Furukawa M, Tasaki T, Sonoda $\mathrm{H}$, Uchida A. Large-scale gene expression profiles, differentially represented in osteoarthritic synovium of the knee joint using cDNA microarray technology. Biomarkers. 2007;12:384-402.

6. Brandt KD, Radin EL, Dieppe PA, van de Putte L. Yet more evidence that osteoarthritis is not a cartilage disease. Ann Rheum Dis. 2006;65:1261-4.

7. Englund M, Guermazi A, Lohmander SL. The role of the meniscus in knee osteoarthritis: a cause or consequence? Radiol Clin North Am. 2009;47:703-12.

8. Seedhom BB, Dowson D, Wright V. Proceedings: functions of the menisci. A preliminary study. Ann Rheum Dis. 1974;33:111.

9. Voloshin AS, Wosk J. Shock absorption of meniscectomized and painful knees: a comparative in vivo study. J Biomed Eng. 1983;5:157-61.

10. Baker BE, Peckham AC, Pupparo F, Sanborn JC. Review of meniscal injury and associated sports. Am J Sports Med. 1985;13:1-4.

11. Garrett WE Jr, Swiontkowski MF, Weinstein JN, Callaghan J, Rosier RN, Berry DJ, Harrast J, Derosa GP. American Board of Orthopaedic Surgery Practice of the Orthopaedic Surgeon: part-II, certification examination case mix. J Bone Joint Surg Am. 2006;88:660-7.

12. McDermott ID, Amis AA. The consequences of meniscectomy. J Bone Joint Surg Br. 2006;88:1549-56.

13. Cullen KA, Hall MJ, Golosinskiy A. Ambulatory surgery in the United States, 2006. Natl Health Stat Report. 2009;11:1-25.

14. Hede A, Larsen E, Sandberg $H$. The long term outcome of open total and partial meniscectomy related to the quantity and site of the meniscus removed. Int Orthop. 1992;16:122-5.

15. Andersson-Molina $\mathrm{H}$, Karlsson $\mathrm{H}$, Rockborn P. Arthroscopic partial and total meniscectomy: A long-term follow-up study with matched controls. Arthroscopy. 2002;18:183-9.
16. Hede A, Larsen E, Sandberg H. Partial versus total meniscectomy. A prospective, randomised study with long-term follow-up. J Bone Joint Surg Br. 1992;74: 118-21.

17. Sandell $\sqcup$, Xing X, Franz C, Davies S, Chang LW, Patra D. Exuberant expression of chemokine genes by adult human articular chondrocytes in response to IL-1beta. Osteoarthritis Cartilage. 2008;16:1560-71.

18. Mesiha M, Zurakowski D, Soriano J, Nielson JH, Zarins B, Murray MM. Pathologic characteristics of the torn human meniscus. Am J Sports Med. 2007;35: 103-12.

19. Fairbank TJ. Knee joint changes after meniscectomy. J Bone Joint Surg Br. 1948;30:664-70.

20. Glasson SS, Askew R, Sheppard B, Carito B, Blanchet T, Ma HL, Flannery CR, Peluso D, Kanki K, Yang Z, Majumdar MK, Morris EA. Deletion of active ADAMTS5 prevents cartilage degradation in a murine model of osteoarthritis. Nature. 2005; 434:644-8.

21. Billinghurst $R C$, Dahlberg $L$, lonescu $M$, Reiner $A$, Bourne $R$, Rorabeck $C$, Mitchell P, Hambor J, Diekmann O, Tschesche H, Chen J, Van Wart H, Poole AR. Enhanced cleavage of type II collagen by collagenases in osteoarthritic articular cartilage. J Clin Invest. 1997;99:1534-45.

22. Poole AR, Kobayashi M, Yasuda T, Laverty S, Mwale F, Kojima T, Sakai T, Wahl C, El-Maadawy S, Webb G, Tchetina E, Wu W. Type II collagen degradation and its regulation in articular cartilage in osteoarthritis. Ann Rheum Dis. 2002;61 Suppl 2:ii78-81.

23. Chia SL, Sawaji Y, Burleigh A, McLean C, Inglis J, Saklatvala J, Vincent $T$. Fibroblast growth factor 2 is an intrinsic chondroprotective agent that suppresses ADAMTS- 5 and delays cartilage degradation in murine osteoarthritis. Arthritis Rheum. 2009;60:2019-27.

24. Majumdar MK, Askew R, Schelling S, Stedman N, Blanchet T, Hopkins B, Morris EA, Glasson SS. Double-knockout of ADAMTS- 4 and ADAMTS- 5 in mice results in physiologically normal animals and prevents the progression of osteoarthritis. Arthritis Rheum. 2007;56:3670-4.

25. Fukui N, Zhu Y, Maloney WJ, Clohisy J, Sandell LJ. Stimulation of BMP-2 expression by pro-inflammatory cytokines IL-1 and TNF-alpha in normal and osteoarthritic chondrocytes. J Bone Joint Surg Am. 2003;85 Suppl 3:59-66.

26. Goldring MB. The role of cytokines as inflammatory mediators in osteoarthritis: lessons from animal models. Connect Tissue Res. 1999;40:1-11.

27. Martel-Pelletier J, Alaaeddine N, Pelletier JP. Cytokines and their role in the pathophysiology of osteoarthritis. Front Biosci. 1999;4:D694-703. 
The Journal of Bone \& Joint Surgery $\cdot$ Jbjs.org VOLUME 94-A - Number 5 - MARCH 7, 2012

28. Chintalacharuvu SR, Wang JX, Giaconia JM, Venkataraman C. An essential role for CCL3 in the development of collagen antibody-induced arthritis. Immunol Lett. 2005;100:202-4.

29. McKinney C, Merriman ME, Chapman PT, Gow PJ, Harrison AA, Highton J, Jones PB, McLean L, O'Donnell JL, Pokorny V, Spellerberg M, Stamp LK, Willis J, Steer S, Merriman TR. Evidence for an influence of chemokine ligand 3-like 1 (CCL3L1) gene copy number on susceptibility to rheumatoid arthritis. Ann Rheum Dis. 2008;67: 409-13.

30. Eggli S, Wegmüller H, Kosina J, Huckell C, Jakob RP. Long-term results of arthroscopic meniscal repair. An analysis of isolated tears. Am J Sports Med. 1995;23:715-20.
Molecular Analysis of Age and Sex-Related

Gene Expression in Meniscal Tears
31. Kotsovolos ES, Hantes ME, Mastrokalos DS, Lorbach O, Paessler HH. Results of all-inside meniscal repair with the FasT-Fix meniscal repair system. Arthroscopy. 2006;22:3-9.

32. Rosner IA, Goldberg VM, Moskowitz RW. Estrogens and osteoarthritis. Clin Orthop Relat Res. 1986;213:77-83.

33. Verbrugge LM. Women, men, and osteoarthritis. Arthritis Care Res. 1995;8:

212-20.

34. Lange AK, Fiatarone Singh MA, Smith RM, Foroughi N, Baker MK, Shnier R, Vanwanseele B. Degenerative meniscus tears and mobility impairment in women with knee osteoarthritis. Osteoarthritis Cartilage. 2007;15: 701-8. 